\title{
MIDDLEMARCH ON SCREEN: FROM THEORY TO PRACTICE
}

\author{
Farideh Pourgiv $^{1}$ and Seyedeh Sara Foroozani ${ }^{2 *}$ \\ ${ }_{1}^{1}$ Prof. Dr., Shiraz University, Iran, fpourgiv@rose.shirazu.ac.ir \\ 2 M.A. Student, Shiraz University, Iran, hforoozanih@gmail.com \\ ${ }^{*}$ Corresponding author
}

\begin{abstract}
Many literary critics refer to the media adaptations of great literary works of literature, as inferior and subsidiary, lacking inborn aesthetic techniques which the original literary text enjoys. Thus, a fundamental question is posed regarding the very source and origin of a literary adaptation; why and how does an adaptation come into being, and what factors are involved in an author's canonization and in a literary media adaptation's success or failure? In response to such central questions, one must refer to an individual's primary fascination with a particular piece of a literary work as a film director, which in turn ends up in a pictorial representation of his/her joyful aesthetic experience, attaining an interpersonal scope through an active participation of an audience. Hence, the current article seeks to discuss how a media adaptation of a great $19^{\text {th }}$ century literary work, like George Eliot's Middlemarch, can operate as a potential means of communication and transformation between the author and the audience, as the original text, through media culture with the help of virtual reality and narratology techniques. In turn, such goals can be achieved by a multidimensional analysis of the mentioned elements through George Eliot's Middlemarch as the original text and its filmic adaptation as an independent work of art.
\end{abstract}

Keywords: George Eliot, Middlemarch, Adaptation, Narratology, Media culture, Virtual reality

\section{AN INTRODUCTION ON $19^{\text {TH }}$ CENTURY THEMATIC PERSPECTIVE}

Generally speaking, it is said that "external factors such as author gender, author nationality, and date of publication", "cultural/historical environment of the author play a [significant] role in determining the choice and relative use of different themes" (Jockers and Mimno, 2011, p. 1). In an attractive discussion on the significant themes of the $19^{\text {th }}$ century, Jockers and Mimno argue that there exist certain "female fashion" (6) and male fashion themes in the literature of Victorian era practiced well by both male and female artists of the time. However, general themes of fashion, children nursery and governess, along with drawing rooms with their opening view to the beautiful nature are more associated with female authors, while more objective themes of pistols \& weapons, soldiers, wars, deep senses of grief, children production, landlord, moments of intense astonishment and confusion are among the most central themes ascribed to male authors.

\section{COGNITIVE AND LITERARY PERSPECTIVE ON ADAPTATION}

Adaptation as the literary critic Linda Hutcheon puts it, is "the simple act of almost but not quite repeating, in the revisiting of a theme with variations" (Hutcheon, 2006, p. 62). But before getting to know the theory of adaption in terms of its cultural and literal meaning, it is vital to have some quick review on the psychological 
aspect of adaptation in an individual's psyche. As Shelley Taylor, an American psychologist points, "the adjustment process [in the human's psyche] centers around three themes: A search for meaning in [individual's] experience, an attempt to regain mastery over the event in particular and over one's life more generally, and an effort to restore self-esteem through self-enhancing evaluations" (Taylor, 1983, p. 1161). The author further asserts that the only potential way for an individual to digest and resolve these three issues "rests fundamentally upon the ability to form and maintain a set of illusions" (Taylor, 1983, p. 1161). But then she narrows down the definition of illusion to a degree which deals with "opposite to known facts rather ... looking at the known facts in a particular light" (Taylor, 1983, p. 1161). She argues that it is through the comprehension of the cause that the effect and its potential symbolic layers of meaning can be perceived by the intellect. So human beings tend to gain control over their life by clinging to diverse "attributions" (Taylor, 1983, p. 1162) which operate based on illusions and it is the illusion that makes "psychological adaptation" (Taylor, 1983, p. 1167) possible.

Greenwald also notes that "maintaining the self as a highly organized information processing system . . . and behavioral persistence" (Taylor, 1983, p. 1168) has its roots in the illusion of control which can be heightened during intense circumstances. In line with the question of the effects media adaptations can have on audiences, one must refer to the time when an individual's illusion gains a mastery over the self becomes a perceiving, controlling and predicting agent of his/her environment, which in turn brings a sense of confidence to an individual. But sometimes an unpredictable event by putting the "emotional, cognitive, and emotional deficits" (Taylor, 1983, p. 1169), as a blocking agent in the process of environment apprehension, can challenge and shatter this sense of mastery and this is what the audience experience more vividly in climatic moments in literary adaptations, since any filmic adaption would definitely "interfere with a world that is treasured and cherished in out [audience's] hearts. An adaptation which does not respond to our personal vision of the book is immediately seen as an attack on our integrity" (Marciniak, 2007, p. 61).

In the discussion of literary adaptation, McQueen suggests that "the question of authorship in adaptation should be understood in terms of what Foucault calls 'founders of discursivity"' (60). Then he clarifies the point by asserting that the "[founder of discursivity] reflects the cultural and authorial vicissitudes characteristics of adaptation discourse" (McQueen, 2012, p. 64); that is, the ultimate author is the literary author, and one must view the director of an adaptation as an author of an independent but analogic text which does not enjoy fidelity in its full sense, since "talent . . . is not a function of fidelity" (McQueen, 2012, p. 69). This demands an independent view toward adaptations and must not be confused with those approaches which regard filmic adaptations as "sycophantic, derivative and therefore inferior to their literary counterparts" (Leitch, 2008, p. 63). McQueen believes that "authors and their name [and also their work] become a [sociocultural] commodity . . . [and the] adaptation is often cynically viewed as the paragon of the commodification of authors and their novels" (63); that is, the audience tends to shape some presuppositions by hearing the name of an author. For instance, one can easily guess the gist of the works written by George Eliot, as primarily concerning realism, class and gender issues. Following the question of the founders of discursivity, one can conclude that the phrase seeks to suggest a sense of "return to the origin . . . a legacy of new readings that in time will be reread and reworked" (McQueen, 2012, p. 65). This in turn clarifies the primary aim of any work of adaptation, which is to shed a new light in understanding the original text, as a "game of discovery" (McQueen, 2012, p. 66).

In terms of literary adaptations, it must be noted that directors can be distinguished as creative artists only if they manage to provide a new narrative style in their adaptations, since media adaptations are considered as "a kind of extension of creative literary authorship that used the camera instead of the pen" (McQueen, 2012 , p. 67) as its linguistic approach, that is the "rhetoric and iconography-that of 'penning' a film- can be understood as a declaration of artisanal equivalency" (McQueen, 2012, p. 67). So what stands out in the discussion of the original writer is the issue of narratology and what distinguishes a media adaptation of a literary work from the source, is the unique style of director. Meaning that directors must not "reduce filmmaking to the mere translation of a pre-existing screenplay" (McQueen, 2012, p. 68), while an adaptation involves both "filmable and unfilmable scenes, and . . . instead of omitting the latter, it is necessary to invent equivalent scenes" (McQueen, 2012, p. 69). In line with what has been mentioned, Thomas Leitch also insist of filmic innovations in adaptations, since there are times that "[n]ovels have to be made shorter [as in the case of Eliot's Middlemarch and its BBC series filmic adaptation], shorter stories have to be made longer and stage plays have to be opened up" (Leitch, 2008, p. 69).

Aside from Cahir's three modes of "Literal, traditional and radical" (Leitch, 2008, p. 71) in literary adaptations, Linda Hutcheon brings about her three mode theory toward the adaptation of a literary work: "the telling mode (e.g. literature), the showing mode (e.g. film or theatre) and the interactive mode (e.g. videogames or theme park sides) [as the final product of adaptation and the most active one]" (65). One of the issues that 
deals mostly with the audience perception concerns itself with the visual issues of the media adaptation. Marciniak says that:

It was an obvious fact that each act of visualization narrowed down the open-ended characters, objects or landscapes, created by the book and reconstructed in the reader's imagination, to concrete and definite images. The verbally transmitted characteristics of the heroes, places and the spatial relations between them, open to various decoding possibilities in the process of imagining, were in the grip of flattering pictures. Visualization was therefore regarded as destroying many of the subtleties with which the printed word could shape the internal world of a literary work only in the interaction with the reader's response (60).

However, some literary critics assert that any product of adaptation lacks the original spirit, thus recognized as "inferior to the adapted text, as 'minor', 'subsidiary', 'derivative' or 'secondary' products, lacking the symbolic richness" (Marciniak, 2007, p. 59) as pointed earlier. There are instances of what Thomas Leitch calls "the failed adaptations" (70) in media productions in which the adaptation fails to notice the appropriateness of the selected genre with the original work of literature, like choosing the genre of animation for depiction of serious realistic works. In response to what they argue, one must question about the clarifying elements within a literary work which has the actual potentiality to insert what they call the spirit. Now a days, adaptations are viewed and analyzed as an independent artifact "caught up in the ongoing whirl of intertextual transformation, of texts generating other texts in an endless process of recycling, transformation, and transmutation, with no clear point of origin" (Stam, 2000, p. 66). However, one can also regard adaptation as an interpretation of an art, namely the literature, which alike other types of the art, welcomes "vast area of communicative possibilities" (Marciniak, 2007, p. 60) and with the illusion representing the meaning in the mind of the audience, thus it is necessary to focus on the "process of reception" rather the "source" (Marciniak, 2007, p. 60). It is interesting to note that adaptation theory puts an emphasis to the adaptation's faithfulness toward its "internal logic" (Marciniak, 2007, p. 61) which is and must be independent of the original logic of the text. Following the goal of creating the new out of the already familiar, Marciniak asserts that:

[The] source of pleasure lies in observing the unity of the artistic communication across media. Films contextualize books in a visible and audible atmosphere and invite us to discover the unsuspected ways of seeing and hearing things. A specific combination of images and sounds can provide insights into the nature of the deep-seated meanings that do not lend themselves easily to verbal exploration. The ideas mystified in symbols and the veiled references to different aspects of life that we once decoded in a particular way speak to us from a new perspective and we learn to appreciate a literary text on a different level, we begin to notice that many of its elements gain a new life when interpreted in the context of the new medium's specificity (63).

There are also other factors in making an adaptation a pleasurable experience. One of the primary factors which deals with the source of pleasure is the very aesthetic experience of the writer, which is the product we mostly recognize as the original source of adaptation. Another element is the "interpersonal" (Marciniak, 2007, p. 62) mutual interactions and communications which opens the gates to the gist of the work and its adaptation. The next factor deals with the potentiality of the media to "bring literature back to its original unity . . . by the physical presence of the performing artist" (Marciniak, 2007, p. 63). Thus, Marciniak proposes to view "works of art . . . as a unity of body and soul, where the mental perception of the world is possible through the unity of senses" (Marciniak, 2007, p. 63). And finally the two other factors in the discussion of the source of pleasure in adaptation are the fluctuation of the "source-adaptation hierarchy" (Marciniak, 2007, p. 64 ) in the novel and in its media adaptation in terms of the absence or creation of characters' role and the scene's significance. And the fifth and the last element is the voice and music in particular. It is believed that thematic melodies "create moods and heighten emotions provoked by the story . . . [it] reinforces the symbolic richness of the literary work ... [and] sheds a new light on its meanings" (Marciniak, 2007, p. 65) and it is the voice effect that prolongs the fascination in the audience's memory.

In response to the debate that concerns what makes a pictorial translation of a work of art a well-received adaptation, is how well the media adaptation hast internalized the gist of the novel as a literary work or as Linda Hutcheon puts, the spirit. In fact it is a matter of levels. One of the most controversial questions which arouses here is that how far is the distance between the imagined picture in the mind of a reader, while reading a novel and the picture he sees during watching the Tv series, after all the screen play and director come from the jargon of the readers, thus their adaptation is viewed to be a sort of review writing on a literary work. 
Another essential point concerns the ultimate "exact models of understanding" (Marciniak, 2007, p. 60) and the united approach of interpretation, visualization and perception of a literary text. Current literary critics do refuse the previous limiting and narrowed approach toward the evaluation of the literary works and adaptations. They regard literature, an artistic artifact, which "suggest a vast area of communicative possibilities" (Marciniak, 2007, p. 60). Further, they argue that adaptations "are now being analyzed as products of artistic creativity ... with no clear point of origin ... [yet it] is seen as interpretation, as a specific and original vision of a literary text" (Marciniak, 2007, p. 60).

On the other hand, Robert Stam believes that "meanings could be seen as events that took place in the reader's time and imagination ... therefore necessary to place the emphasis differently, not on the source, but on the way its meanings were reconstructed in the process of reception" (Marciniak, 2007, p. 60). Hence, it is natural to judge an adaptation of a literary works based on the level of its closeness to the original text. However, adaptations are regarded as one of the possible independent interpretations of the literary text which must be simply accepted, "[e]ven if the film maker's reading of a given literary text clashes with our reading" (Marciniak, 2007, p. 61), with almost no further judgments, as far as the adaptation "remain[s] faithful to the internal logic created by the new vision of the adapted work" (Marciniak, 2007, p. 61).

Marciniak offers an interesting discussion about how the audience react differently when interacting with those adaptations of the books which they are fund of. The author then proposes that there are two possibilities for the adaptation of an appealing work of art. Either it fails in attracting the potential audience if the adaptation "does not respond to our personal vision of the book" thus, it is "immediately seen as an attack on our integrity" (Marciniak, 2007, p. 61), or the adaptation brings a success in its artistically skillful "interfere with a world that is treasured and cherished in our hearts" (Marciniak, 2007, p. 61). Hence, any violation of the audience's sense of confidence toward the work's story would definitely ends up in the adaptation's failure. However, it must be noted that such issues must not block the path of creativity in adaptations while adaptations are to "add some freshness to the familiar world" (Marciniak, 2007, p. 62).

\section{THE REAL PERSPECTIVE ON VIRTUAL REALITY AND FICTION IN ADAPTATION}

However, in line with their social didactic style in fictional characterizations, it seems that the $19^{\text {th }}$ century canonized "authors of narratives (whether oral, dramatic, or written) use enough realism to make their stories believable, but also exaggerate or understate the role of character traits in life outcomes to evoke thoughts and feelings that encourage certain behaviors in the audience" (Johnson et al., 2010, p. 1).

The controversial concepts of real and realism have still remained as those of the most fundamental questions in the discussion of media and literature. What is real? What elements differentiate between illusion, fiction and the reality? And what is virtual reality? These are the most basic questions in the discussion of realism on which many critics have sought to bring a convincing definition. Moreover, new subcategories of realism, the most significant of which is the modern term of virtual reality, have added to the complexity of the issue, beside the discussion of its Victorian counterpart, which tend to amalgamate what is real as an existing concept, with those "'virtual' and 'tele' ... [as a] deviation or distance from reality" (Niiniluoto, 2011, p. 14).

Virtual reality, a modern term first coined by Jaron Lanier, is defined as possessing a three dimensional entity which enjoys the potential capacity of interacting with its seemingly real physical target, by the help of special electronic equipment. These technological devices "resemble the participant's [the audience] normal interface with the physical environment and thus he feels himself immersed in a new "reality"' (Niiniluoto, 2011 , p. 14). Technologically speaking, virtual reality is recognized as a media art that "can be assessed by various criteria which include economy, efficiency, aesthetics, ergonomics, ecology, ethics, and social effects" (Niiniluoto, 2011, p. 14). The purpose of virtual reality as Niiniluout points, concerns three fields of human "entertainment", "a way of escape and addiction" and "ethical and social" (14).

One of the highly controversial questions raised is "whether artificial intelligence [namely, techniques of virtual reality] merely pretends or 'really' is intelligence . . . [and also] whether virtual reality is 'really' real or not" (Niiniluoto, 2011, p. 15). However, Heim tends to define the modern concept as "not actually, but as if" (Niiniluoto, 2011, p. 15) phenomenon.

Following the discussion of virtual reality, its definition and application both in literature and media, the current article seeks to bring its own ideologies about this issue by pointing to some of the major existing differences or similarities between the fiction, imagination and the reality. Entities do come into real existence, when they possess the two vital criteria of time and space. Nevertheless, it remains quite independent of other associated entities, since it is a highly subjective and flexible concept. Niiniluoto points 
to an interesting quotation in his article, which makes the relationship between the fiction and reality clearly comprehensible. He writes:

According to Karl Popper's (1979) useful classification the domain of reality can be divided into three parts. World 1 consists of physical objects and processes, World 2 contain mental status and events within a human mind and World 3 include human-made artefacts and socially produced institutions. Thus stones, atoms, and fields of force belong to World 1; beliefs, wishes, feelings and emotions belong to World 2; works of art, scientific theories, propositions and other meanings of linguistic expressions, natural numbers and social institutions belong to World 3. In the additional terminology, the popperian three-fold ontology corresponds to the division between nature, consciousness, and culture and society (15).

Considering the three phases of reality, it must be pointed out that although each of the three worlds show highly independent specialized characteristics, it seems that they enjoy an interrelated connection. It is also worth mentioning that "against Platonist version of realism, such World 3 entities are regarded as humanmade social constructions ... . [while in sharp contrast] World 1 exists independently of human minds, languages, and societies" (Niiniluoto, 2011, p. 16). In a parallel way with the 'as if' dimension of virtual reality, another modern controversial issue is brought up, which assumes fiction and fictional entities, names and places as real, but "not necessarily actual or existing ... . [as] a composite of all objects and states of affair which are logically or conceptually possible" (Niiniluoto, 2011, p. 17). Here, the question of individual's authenticity of apprehension finds voice, which mostly concentrates on the relationship between World 1 , as the world of physicality and World 2 as its mental processor. It is believed that the interconnections of these two worlds makes human psyche a pre-judgmental entity which assumes new data as an already comprehended information.

The next point deals with the differences between the reality and what we call illusion and imagination. As Niiniluoto categorizes, "[a]cts of imagination may be voluntary (fantasy, daydreaming) or involuntary (dreaming)" (19). On the other hands, illusions occur when an individual assigns false characteristics to an entity. It is highly interesting to note that in discussions of media, illusions are not deceptive, since the audience are always aware of the impossibilities of physical entities in surpassing the time or space in their actual sense; hence as Niiniluoto also argues, such visual illusions meditate the casual links between the impossible and possible entities by artificial techniques, like virtual reality, thus making the impossible, probable and actual real. Such modern techniques have been used very much in media, as the methods of "artistic representation to reality" (Niiniluoto, 2011, p. 23). By referring to artistic representation, as a fictional entity which can exists but does not necessarily, many literary critics believe that every work of fiction must enjoy senses of "verisimilitude" (Niiniluoto, 2011, p. 23), making us able to assign it relatively to the real world, since every genre of artistic works are believed to be the internal or external manifestation of their creator.

To apply the concept of verisimilitude to media and to cinema in particular, Niiniluoto points that "[c]inema is like a dream: it creates an illusion of reality, a virtual present where the moving camera takes the place of the dreamer" (23); however, what differentiates reality from cinematic dreams, is the director's controlling power over the dream's content and the frequency of its incidents and of course over the audience's comprehending psyche. Niiniluto also asserts that "our cultural products or 'hyperreal' signs do not any more reflect a basic existing reality or even mask or prevent it, but rather 'mask the absence of reality"' (25). In this sense, it seems quite logical for a fictional work of art to contain intentional instances of illusion for the sake of getting more and more close to the real world and attain the ability of interaction with real entities. However, such idealistic goals seems unachievable for a fictional artifact, since the audience choose to enter the reign of fiction quite consciously. It is true that art can become very close to the reality with the help of post-modern technologies, but still it seems that a work of art must be viewed as merely proposing a window toward the possible world, and not the actual real world.

\section{SOCIOCULTURAL PERSPECTIVE ON MIDDLEMARCH ADAPTATION}

Mass media, as the byproduct of the modern culture and its inevitable part, concentrates itself on middle class families, as its major audience. Thus, almost all of the media productions seek to appeal the taste of the middle class as their primary goal. However, the issue of social elite celebrities, or what we call canons in terms of literature, is among the byproducts of the mass media as a matter of fact. Mass media is said to be covered by a more general term, called media culture, which tends both to reflect and create culture in a society, even though some sociologist argue that no specific media culture exists in today's world, while the audiences have the instant access to diverse international cultural products. In this regard, they believe in a 
single culture existing in the global village. Another fundamental point in media culture and mass media, are the sociological perspectives on media; the limiting theory, the class domination theory and the cultural theory. To put it in nutshell, these three main approaches assume that a minor group of elites in every society have the ultimate power in politics, culture and the media of their people, thus they define and dictate or censure the genre and frame works of the cultural productions based on their religious, political view which is highly individualized. In response to such theories, many sociologists and anthropologists argue that it is not actually the case by bringing lots of instances from media production failures. They assert that such failures are the outcome of ideological contradictions with the social culture, which means that sociocultural tastes of the audience and artists are historically constructed and complex issues, hence do not always follow the minor group ideologies.

Being recognized as the most influential representatives of "cultural pedagogy" (Kellner, 2012, p. 1), mass media and its products "contribute to educating us how to behave and what to think, feel, believe, and desire ... how to be men and women ... and how to conform to the dominant system of norms, values, practices, and institutions" (Kellner, 2014, p. 1). These in turns shape our social and individual identities, "our sense of selfhood . . . our sense of class, of ethnicity and race, of nationality, of sexuality; and of 'us' and 'them'" (Kellner, 2014, p. 1). It is interesting to know that media functions based on and through the most innate shared sources based on which individuals construct the culture or as Douglas Kellner puts it common culture (1). In another sense, media is the omniscient manifestation of the power combat between the dominant system and the marginalized ones. It is also the powerful dictating agent through which we tend to criticize the surrounded world and re-evaluate the deepest moral humanistic values.

Many sociologists argue that it is the culture that "constitute distinct forms of identity" (Kellner, 2014, p. 2) and behavioral attitudes. However, in line with the concepts of high culture and low culture, there exist mainly two approaches within the issue of media culture. One would either belong to the mainstream or the "dominant" (Kellner, 2014, p. 9) readers who "follow the [so-called dominant standard social rules and values and enjoy its restoration] dictates of media culture" (Kellner, 2014, p. 2), or become a member of the opposing side who "identify [themselves] with subcultures" (Kellner, 2014, p. 2) and "observe resistance to dominant readings" (Kellner, 2014, p. 9). Hence, the controversial issue is that "whether the resistance, oppositional reading, or pleasure in a given experience is . . emancipatory or destructive" (Kellner, 2014, p. 10). This further provides the sociologist with the reason why they believe that for the evaluation of any sort of art, one must be familiar with the social, economic and political context of the work's time and "the whole range of culture without prior prejudices" (Kellner, 2014, p. 2). It is highly paradoxical however that the pop cultures are not usually the subordinate representatives of the time as one would consider at first sight, rather they are "often liberal . . . [and] express more radical or oppositional views" (Kellner, 2014, p. 2) with their focal point on racist, class clash and gender based marginalization as a matter of fact.

Following the cultural issues discussed earlier, media seeks to play a pedagogical role of making "people sensitive to how relations of power and domination are 'encoded' in cultural texts such as those of television or film" (Kellner, 2014, p. 3), in line with its own political and economic policies. Media policies lies in highly complex and specific "formula and conventions of production" (Kellner, 2014, p. 4) and whatever production is in the service of the "demands of the format" (Kellner, 2014, p. 4), the most significant one is the highly standard time restriction format anticipated for every single genre of media. Another example of such formats would be the "formulaic conventions, and well-defined ideological boundaries" (Kellner, 2014, p. 5). But dealing with the textual and adaptive analysis of the Eliot's Middlemarch, the use of sign system as the "linguistic and nonlinguistic cultural" (Kellner, 2014, p. 6) ruling power seems undeniable both within the novel and its media adaptation. Such formulaic conventions operate based on a specific critical approach which in turn "focuses on certain features of a text from a specific perspective . . . while ignoring others" (Kellner, 2014, p. 7). But, audiences' role in "media texts" (Kellner, 2014, p. 7) must not be forgotten, since reaching responses is only possible through the analysis of both the physical and intellectual influences media has on its audience. After all, it is the audience and his/her taking side that ends up in his/her creation of meaning and identity, thus demands distinct "cultural forms", "as an escape from the demands of a disciplinary society" (Kellner, 2014, p. 8).

Speaking of the cultural aspects of media and the roles it functions on its audience, it seems quite appropriate and significant for the current article to bring its own minor criticism on Davies and Page's version of Middlemarch adaptation, which does not seem to concern itself with the manifestation of sex issues in the film adaptation, which is believed to be highly in contradiction with the moralistically conservative atmosphere of the Victorian era literary works and also quite in sharp contrast to the most important adaptation rule that insists on the honest responsibility and faithfulness of any kind of adaptation toward the original literal work in all terms, specifically in thematic issues. 


\section{NARRATOLOGICAL PERSPECTIVE ON GEORGE ELIOT'S MIDDLEMARCH}

What makes an author and his/her work worthy of attention and adaptation? It is interesting to remind that literary adaptations are generally chosen from canons of literature. In this sense, becoming a popular author, demands a creative talents in storytelling. One of the issues that has made George Eliot, an outstanding and a leading figure in Victorian literature and in comparison to those elite writers of her time like Dickens, lives in her literary approach and writing style. She is a realist who concentrates on certain focal themes of landscape, gender and class issues in almost all of her works. In general sense, Victorian artists were obsessed with the literary manifestations of the $19^{\text {th }}$ century daily life incidents, through a didactic spectacles. Talking about George Eliot's literary innovation, one must point to the very differential point that lies in Eliot's literary goal. In a sharp contrast with great authors like Dickens, and in a quite parallel way with the French and Russian movement toward the Modern Novel, George Eliot's works enjoy a radical $19^{\text {th }}$ Century codes of morality and literary gravity. Eliot's radical practices on moral religion led her to the detachment of religion in its objective sense. By so doing, George Eliot insists on the concept of morality as every individual's sense of duty in a socio-humanistic scope. She believes that such concepts must be practiced at service of people.

Despite the fact that critics generally consider George Eliot's works as being covered under the umbrella term of realism, it is interesting to note that the essences of Naturalism can also be felt in Eliot's works almost equally in her setting depictions. Of course one point must be clarified here that George Eliot's realism lies mainly in her middle class centered characterization. On the other hand, her naturalism is regarded to be an altered narrowed down version of the school of naturalism in its broad sense. As a responsible author toward her nation, Eliot was a faithful advocate of the belief in cause-and-effect, along with the rules of determinism. Eliot puts it even further and approaches her character's vices and virtues in a deep serious manner by the use of the catharsis in her works. She sought to bring about the gist of the real, by practicing naturalism. It is true that George Eliot did not deny the inevitable existing bipolar forces within and without an individual, yet she constantly seeks to remind us of an individual's moral duty toward his/her fellow men.

George Eliot's Middlmarch is the manifestation of her powerful creative psyche, represented so skillfully through an extensive scope, which in turn has digested four different versions of stories, with Dorothea Brook's story as the first and the central one, and then life stories of Dr. Tertius Lydgate, Mary Garth and the banker Mr. Bulstrode. In her Middlemarch, Eliot has sought to create and portray a social character through her characterization of Dorothea; the one with great social goals of good moral conducts and serving her people, despite those constant inevitable and imposed forces of the society and also internal forces. Interestingly enough, this seems to be the very reason behind her depiction of Middlemarch, as a provincial experience, to be able to manifest the potential influence of the interrelation of character's life as a minor society who lives within a major society and at the same time to avoid mono hero/heroin depictions far from social concerns. As referred to earlier, Eliot argues that we have duties toward the lives of other people, except for being responsible toward our own lives.

Another interesting point concerning the Middlemarch's debate, is that her current artifact is proved to have been quite distant from issues of biased sexism. She depicts both a male and a female character as her central figures, with almost the same ideological trends of intellect and emotions. Both are so much concerned with social issues of the town; however, they both lack the realistic life vision. Both Dorothea and Dr. Lydgate are idealists and this very issue is considered to be their tragic flaw. She introduces her readers to an individual's inborn nature, the time and setting, as the factors which are the potential representatives of destiny in its practical sense.

Talking about George Eliot's art of storytelling, it seems inevitably crucial to point out to some amazing features of her narrative style, the most important of which is the use of third person omniscient narrator which provides the reader with "a view point from an all-knowing and unnamed person, as narrator and author are seen as one and the same" (Carter, 2012, p. 2). This technique is proved to have been performing in favor of Eliot's realism throughout her novels. It is interesting however to refer to the artistic methods she chose for going in and out of her character's psyche and reporting events and internal feelings, while seeming natural for the audience through standing aloof from imposing any inexpert impression of artificiality or fictionality in her works.

In continuum to Eliot's artistic techniques in storytelling, the issue of sexism as briefly mentioned earlier, is another outstanding point in George Eliot's Middlemarch. Many critics believe that "female or male perspective" (Carter, 2012, p. 2) is vaguely a matter of debate in Middlemarch. No audience or literary critic can be certain if the narration is of Eliot's the creator, or it refers to a specific female/male character while reading her work. Carter argues that Eliot's audience "are only able to ascertain certain characteristics as 
they relate to [female's] emotional traits ... or on the [male's] intellectual traits" (2). Carter afterwards brings about a highly interesting speculation on the "dichotomy of the possible male/narrator and female/author, taking place at the same times" (3). Hence, he asserts that such dichotomies operate on the favor of Eliot's gender-neutral storytelling, primarily to put forward the traditional issue of male's intensive and further to use such concepts at the service of feminism for proving Victorian female writers' mastery in the second place.

Carter also adds that "Eliot dismissed the conventions of authority, accomplishing her intent of blurring the gender lines" (Carter, 2012, p. 3). In fact it was the existing atmosphere of change that made such practices of "novel as a political platform" (Carter, 2012, p. 3) possible for Victorian female writers to put different social discourses into trial, and this seems to be highly in line with what Carter below refers to in her article of the role that the $19^{\text {th }}$ century female writers like George Eliot played through the great power of their words and their influential pens.

The narrator is a character as well, and one which can be widely manipulated. As a character which seems almost independent of the author and novel itself, the narrator's views and interpretations can be removed from that of the author, making this character highly desirable in which to use as a vehicle for challenging social construction. In harnessing their own power and finding their own voice in ... [and] paradoxically offer a potential meditating ground for transforming [in Lansern's word] 'the sex' -a caste into a 'we,' a 'body politic'. Women's bodies of literature were then extended far beyond simplistic and whimsical fancy, it also offered a way to expose constructed views and values and lent authority, power, and privilege to a community of women would not have been able to attain it elsewhere (Carter, 2012, p. 4).

Dealing with a literary work of art, adaptation is regarded as the stage where literature and media get mingled in the way that it seems hard for the public readers to distinguish which one is the adaptation of the original. However, there are significant methods through which one can come to a conclusion on the differences and similarities which exist in between. One of the most important and controversial factors is the issue of narratology. In terms of literature, there exists two main voices within every piece of literary work, "authorial and narratorial" (Cardwell, 2013, p. 116); both with operating highly in parallel with the overall structural, "the mood or tone" (Cardwell, 2013, p. 116) and the thematic frame work chosen by the author. Narratology studies focuses on the vitality of the readers' perception of the meanings and making sense of the literary work, since each one "of those voices has a discernible character, and each expresses an attitude towards the events and characters depicted" (Cardwell, 2013, p. 116). But, things gets a little different when it comes to media and television in particular. Both authorial and narratorial voices do exist in media as well, but there are certain minor differences while dealing with the issue of mass media narratology. Technically speaking, the authorial tasks are done independently and outward of the film production process, thus it gives the impression that the "unravelling authorial and narratorial functions and voices are rather trickier" (Cardwell, 2013, p. 116). To make the distinction between the narratorial and authorial more clear, Cardwell argues that:

When the viewer perceives a strong sense of premeditation or intention within the programme, it directs his/her attention outside the text, and they detect an authorial influence or voice. However, once the authorial role has been undertaken and completed, commentary can be created that exists only within the text [which may not even be the author's intention] . . . so voice incorporates the literal voices/points of view present within the work through the characters, and more obscure voices including the narrator and Davie's [the screenplay writer of the adaptation of Middlemarch] own authorial voice (116).

Brian McFarlane further discusses one of the most important elements which helps distinguishing narratology, in literature and audio-visual media, such as television and film adaptations as "the difference between telling and presenting (or showing) a story, and [he] pinpoints . . . the narratorial voice (the voice through which the story is told) as one of the salient features that distinguishes novels from their screen adaptations" (Cardwell, 2013, p. 112). McFarlane declares that:

[One] aspect of the distinction between telling and presenting is located in the way in which the novel's metalanguage (the vehicle of its telling) is replaced, at least in part by the films' mise-en-scene. In a sense the film's story does not have to be told because it is presented. Against the gains in immediacy, the loss of the narratorial voice may, however, be felt as the chief casualty of the novel's enunciation (29).

In continuum to the discussion of narratology and storytelling techniques used in Middlemarch, the current article seeks to have an analytical and comparative look at the functionality of such techniques in the BBC series film adaptation of the Middlemarch, directed by Anthony Page. However, there are certain issues to be 
discussed prior to the analysis of Anthony Page's adaptation of George Eliot's Middlemarch, which focuses on the very nature of media adaptations in its general sense and BBC Corporation in particular. The first point is the issue of target. Target in media term is defined to be the majority of people as audience which come from varieties of nations and backgrounds and with diverse ideologies, yet they all share a specific social umbrella term called popular culture. So it seems that the emergence of such "large-scale Tv" (Chase, 2006, p. 181) programs, like those of the BBC, have been to satisfy the "pop culture" (Chase 181) taste. Another natural characteristic of media lies in the way it mingles both the dialogue and different types of conflicts to enjoy the "dramatic" (Chase, 2006, p. 181) effect it seeks. Hence, in line with its dramatic sceneries, it is believed that all Tv serial corporations follow the specific framework of putting "heightening of suspense at the end of each episode" (Chase, 2006, p. 181) to attract and respond to the expectations of a pop culture audience.

Pointing out some of their most important techniques used in the BBC series adaptation of Middlemarch seems inevitable. In line with their consideration of the target audience as the primary aim of such mass media corporations like BBC, Anthony Page has chosen the first limiting approach toward the issue of the audience's toleration level; thus "he manages to present and in some cases intensify many of the observations and reflections that Eliot makes her narrator share with the reader" (Chase, 2006, p. 181), in line with his usage of diverse aesthetic techniques and genres. For instance:

Whereas the readers' impression and understanding of a character like Dorothea is guided by the third-person narrator's account of not only her speech and action but also her thoughts and feelings, the viewer's impression is formed by a subtle combination of visual and auditory signals. Enriching and modifying each other both structurally and thematically ... for example Dorothea's facial expression that moves significantly beyond what is displayed on screen (182).

In terms of media and visual arts, it is so much said that the camera becomes both the narrator and the narrated story itself through the amalgamations of auditory and visual techniques. David Bordwell believes that there exists no other potential narrator, thus insists on the active involvement of the audience, since "in watching films, we are seldom aware of being told something by an entity resembling a human being" (62). However, it is in fact the case that the audience tends to create his/her own emotional version of the meaning under the influence of those audiovisual elements and then comes to grasp the more realistic meaning of the film through following the story line. Putting aside the subject matter of the existing discrepancies between the tradition and the modernized London through the manifestations of Dr. Lydgate and the railway system, Anthony Page's adaptation techniques, concerns itself mostly with the different possible methods of "translation and transformation, including the problem of knowing ourselves and those around us" (Chase, 2006, p. 193). This is actually highly in line with how Kay Young also discusses this issue by saying that "looking to 'see' the consciousness of another as a means of knowing another means seeing the other through the lens of the self. Seeing involves a negotiation between image and its analysis, an analysis based on the seer's past knowledge [as we refer to the word 'seem' as a memorial or to refer to something as a specific point of time/place] or experience or desires" (227).

From a technical point of view, many critics believe that Davie's style and approach in media is toward the creation of the narratorial voice "a voice that presents the story to us, simultaneously offering its own point of view up on the action" (Cardwell, 2013, p. 112), as it is the case with the adaptation of Eliot's Middlemarch as well. It is almost safe to say that in adaptation, it is the camera who tends to narrate the work mostly, but sometimes the question of who is or are speaking and the possibility of the author and narrator's voice amalgamation becomes so complicated that "this [narratorial voice] may appear to be indistinguishable from the authorial voice [and the writer of the work] . . . [h]however, in other instances [of the presence of an unreliable narrator] a novel might be written from the point of view of a fictional narrator- a character invented by the real author" (Cardwell, 2013, p. 113).

In line with Page's approach and in continuum to the controversial subject matter of camera narratology, translation and transformation, Karen Chase asks a question about the limitation level of the camera and the authenticity of its pictorial narrations. She asserts that:

The camera eye is mechanical, it has its own way of seeing the world, and there is something refreshing deanthropomorphizing about it that contrasts with the way human beings see. The camera can, for instance, focus on details not noticed by the human eye. And yet we must not forget that the camera is after all steered by a photographer, and behind him or her a director [with their special personal and subjective perspectives that affects they approach] . . . [however] the film camera can register the effect of seeing one character on another in a manner that makes visually accessible to the viewer a double 
image, that of the figure of known along with that of the figure of knowing [achieved by Anthony Page by his depiction of medium and almost long shots during his film making] (193).

Dealing with Middlemarch film adaptation, on the first hand, it seems that the audiences are watching the film through a single united view angle. However, to many audiences' amazement, it is in fact not the case. Technically speaking, we are dealing with a multi camera style of camera working while watching the Middlemarch adaptation. Each specific perspective observes a single entity, namely a setting or a character, from a unique approach. It is interesting to note that the story is filmed by the use of stablishing multiple professional cameras in different angles within a setting and then shifting from one scene to another, during the filming process. This in turn provides the camera and the director with a power mastery over the whole story transmission and its narratology transformation.

Aesthetically speaking, Davies' version of Middlemarch came to be a success for being recognized as "a careful, responsive adaptation" (Cardwell, 2013, p. 118), well perceived by the potential audience and also for the good performance and wise choice of camera directions, settings and its associations. Such an "uncomplicated approach to the adaptation emphasized its novelistic roots, guiding our attention to the dialogue, to the rhythms and tensions it creates" (Cardwell, 2013, p. 118). Robin Nelson further praised Davies and Page's depiction of "slow pace", "long scenes" with "limited [few in number of shots] cutting", "because it encourages a similar response and engagement from viewers to that elicited from readers of the novel" (Cardwell, 2013, p. 118), through clinging to the original text's "moral seriousness" (Cardwell, 2013, p. 118). It is also noteworthy to Andrew Davies' fame for his character depiction of "powerful female protagonists [who] are both expressive yet simultaneously constrained by societal mores and the generic conventions" (Cardwell, 2013, p. 117).

In conclusion, it must be mentioned that an adaptation must be viewed as an independent work of art, which enjoys the potentiality of transmission and interpretation of the original literary work as well. However, it in most cases, media adaptations are forced to neglect or over emphasize certain aspects in the author's narrative style for the sake of achieving effective mute close ups through the use of audiovisual filming techniques. Besides, there are sociocultural, ideological and conceptual issues to consider in the discussion of media pop culture and social studies, while dealing with modern and postmodern filmic adaptations of the literary works, belonging to the previous centuries. Nevertheless, any work of adaptation must show high degrees of respectfulness and loyalty toward the original work, in its major constitutive parts, especially in its basic communicative approaches, even though it is considered to be an independent artifact.

\section{REFERENCE LIST}

Bordwell, David. (1985). Narration in the Fiction Film. Madison: University of Wisconsin.

Cardwell, Sarah. (2013). Andrew Davies TELEVISION SERIES. Manchester University Press.

Carter, Jennifer. (2012). "The Art of Storythelling: Women's Nineteenth Century Fictional Narration." The California Journal of Women Writers, 19 (7).

Chase, Karen. (2006). Middlemarch in the Twenty-First Century. Cambridge.

Greenwald, A. G. (1980). "The Totalitarian Ego: Fabrication and Revision of Personal History." American Psychologist, vol. 35.

Huszar, Erika. (2011). "What Is Translated From Novel to Film? Some Criticism of Brian McFarlane's Adaptation Analysis Method." Sino-US English Teaching 8 (8).

Hutcheon, Linda. (2006). A Theory of Adaptation. New York: Routledge.

Jockers, Matthew L. and Mimno, David. (2012). "Significant Themes in $19^{\text {th }}$-Century Literature." Faculty Publications-Department of English, 8 (1).

Johnson, John A., Carrol, Joseph et al. (2010). "Portrayal of personality in Victorian novels reflects modern research findings but amplifies the significance of agreeableness." Journal of Research in Personality.

Kellner, Douglas. (2014). The PhiPapers Foundation. Web.

Leitch, Thomas. (2008). "Adaptation Studies at Crossroads." Adaptation, 1 (1).

McFarlane, Brian. (1996). Novel to film: an introduction to the theory of adaptation. Oxford: Clarendon.

McQueen, Sean. (2012). "Micheal Foucault's 'What is an Author?' and Adaptation." COLLOQUY Text Theory 
Critique, vol. 24.

Marciniak, Małgorzata. (2007). "The Appeal of Literature-to-Film Adaptations." Lingua ac Communitas, vol.17.

Niiniluoto, Ilkka Maunu. (2011). "Virtual Worlds, Fiction, and Reality." Discusiones Filosoficas 12 (19).

Stam, Robert. (2000). "Beyond Fidelity: The Dialogics of Adaptation." Film Adaptation. Ed. James Naremore. New Brunswick: Rutgers University Press.

Taylor, Shelley E. (1983). "Adjustment to Threatening Events- A Theory of Cognitive Adaptation." American Psychologist 38 (11).

Young, Kay. (2003). "Middlemarch and the problem of Other Minds." Literature Interpretation Theory, vol. 14. 